Short-Term Physical and Psychological Management and Secondary Prevention of Self-Harm in Primary and Secondary Care. Stanley Hunt.

original papers rules: the intervention and prevention strategies used by psychiatric nurses working with non-suicidal self-harming individuals. Journal of Psychiatric and Mental Health Nursing, 14, 64-71.

POTTER, M. \& DAWSON, A. (2001) Coercion in mental health care: the principle of least coercive care. Journal of Psychiatric and Mental Health Nursing, 10, 167-173.

O'DONOVAN, A. (2007) Pragmatism
From safety contract to safety agreement. Journal of Psychosocial Nursing and Mental Health Services, 40, 12-13.
SHEPPARD, D. (1996) Learning the Lessons (2nd edn). The ZitoTrust.

UNITED NATIONS (1973) Human Rights: A Compilation of International Instruments of the United Nations. United Nations.
WALLACE,T., ROBERTSON, E., MILLAR, $C$., et al (1999) Perceptions of care and services by the clients and families: a personal experience. Journal of Advances Nursing, 29,1144-1153.

*Camilla Langan Clinical Research Fellow, Department of Psychiatry, Clinical Science Institute, National University of Ireland, Galway, Ireland, email: camilla. langan@nuigalway.ie, Colm McDonald Professor of Psychiatry, Department of Psychiatry, Clinical Science Institute, National University of Ireland, Galway

\title{
Comparative survey of comorbidities in people with learning disability with and without epilepsy
}

\section{AIMS AND METHOD}

To ascertain the prevalence of epilepsy and understand the differences in the comorbidities of non-epileptic and epileptic patients with learning disabilities. A simple comparative survey was undertaken between the two main groups of patients: nonepileptic and epileptic.
RESULTS

The prevalence of epilepsy in the study group was $30 \%$. A total of $70 \%$ of patients with any type of challenging behaviour were in the non-epileptic group compared with $59 \%$ in the epileptic group. Depression was the most common diagnosis in both groups, being slightly more in the non-epileptic group.

\section{CLINICAL IMPLICATIONS}

Our study suggests that there is no association between epilepsy and the prevalence of challenging behaviour of psychiatric conditions within the learning disabilities population.
The reported prevalence of psychiatric illnesses among adults with learning disabilities varies widely between 10 and 39\% (Deb et al, 2001). Estimated prevalence rates for specific conditions are: schizophrenia 3\%, bipolar disorder $1.5 \%$, depression $4 \%$, obsessive-compulsive disorder 2.5\%, dementia 20\%, and autism 7\% (Cooper \& Bailey, 2001). The prevalence of epilepsy in learning disability is said to be $20-30 \%$. Challenging behaviour has a prevalence of $10-15 \%$ and is more common in men than in women. It reaches a peak by 15-34 years of age and increases in severity relative to the level of learning disability. Problem behaviour tends to be long-lasting and more than one type of behaviour is usually found (Smiley, 2005)

A study by Turkistani (2004) looked at the prevalence of epilepsy in learning disabilities and its association with mental illness and behavioural problems. The study found no significant association between epilepsy and behavioural disturbances or mental illness and concluded that epilepsy does not necessarily increase the incidence of mental illness and/or behavioural disturbance. Furthermore, Chung \& Cassidy (2001) concluded in their study that there was no significant difference in the degree of learning disabilities between epileptic and nonepileptic groups. In a cross-sectional analysis, Tyrer et al (2006) found no relationship between aggression and the presence of epilepsy or autism. Similarly, Kerr (2002) concluded that behavioural disturbance is independent of epilepsy or its management. On the other hand, Espie et al (2003) found that a third of people with epilepsy and intellectual disability met the criteria for possible psychiatric disorder, particularly affective/neurotic disorder; twice the comparison rates for intellectual disability alone.

The Community Learning Disabilities Team in Waltham Forest caters to a total population of about 218000 . The region has a multi-ethnic population with Afro-Caribbean groups forming at least $14 \%$, and Asian groups forming $12.5 \%$ of the overall population (Office for National Statistics, 2003; London Borough of Waltham Forest, 2007). The main aim of the study was to ascertain the prevalence of epilepsy and the difference in morbidities between epileptic and non-epileptic individuals in contact with the learning disability service. We also postulated that there is no association between epilepsy and high prevalence of psychiatric morbidities and/or challenging behaviour in our learning disability population.

\section{Method}

At the time of the study there were 353 individuals with learning disabilities in contact with the service. A total of 177 case notes belonging to active clinical cases were included in the study. Information gathered from the case notes was collected in a pre-formatted data collection sheet, where it was placed in the following categories: gender, date of birth, ethnicity, residential status and diagnosis (including epilepsy, psychiatric diagnosis and challenging behaviour). These data were tabulated to 
Table 1. Demographic details (total case notes $n=177$ )

\begin{tabular}{|c|c|c|}
\hline & $\begin{array}{c}\text { Non-epileptic } \\
n(\%)\end{array}$ & $\begin{array}{c}\text { Epileptic } \\
n(\%)\end{array}$ \\
\hline \multicolumn{3}{|l|}{ Gender } \\
\hline Male & $65(52)$ & $30(57)$ \\
\hline Female & $59(48)$ & $23(43)$ \\
\hline \multicolumn{3}{|l|}{ Age, years } \\
\hline $17-24$ & $24(19)$ & $9(17)$ \\
\hline $25-34$ & $18(14)$ & $8(15)$ \\
\hline $35-44$ & $28(23)$ & $9(17)$ \\
\hline $45-54$ & $27(22)$ & $10(19)$ \\
\hline $55-64$ & $17(14)$ & $9(17)$ \\
\hline$>65$ & $10(8)$ & $8(15)$ \\
\hline \multicolumn{3}{|l|}{ Ethnicity } \\
\hline White British & $71(57)$ & $33(63)$ \\
\hline Afro-Caribbean & $20(16)$ & $6(11)$ \\
\hline Asian & $12(10)$ & $8(15)$ \\
\hline Other & $11(9)$ & $6(11)$ \\
\hline Unspecified & $10(8)$ & 0 \\
\hline \multicolumn{3}{|l|}{ Residential status } \\
\hline Residential home & $56(45)$ & $25(47)$ \\
\hline Supported living & $19(15)$ & 7 (13) \\
\hline Private home & $47(38)$ & $20(38)$ \\
\hline Unspecified & $2(2)$ & $1(2)$ \\
\hline Total & $124(70)$ & $53(30)$ \\
\hline
\end{tabular}

ascertain the differences in the above parameters between epileptic and non-epileptic service users.

\section{Results}

\section{Demographic details}

The prevalence of epilepsy in the study group was 30\% (Table 1). There were more men ( $n=95)$ than women $(n=82)$ in the study; there were also more men than women in the epileptic group (30 v. 23). The 10-year age distribution across the two groups was almost equal in all age ranges, except in the 35-44 years old, and above 65 years old range. In the former, more users were nonepileptic while in the latter more were epileptic. Ethnically, White British service users were more likely to be epileptic, whereas this was not observed in the AfroCaribbean group. In the Asian group, Pakistani service users were over-represented in both groups ( $67 \%$ of all Asian users in non-epileptic and $75 \%$ in epileptic group). Others included diverse groups such as mixed Italian and Spanish, Turkish, Cypriot, Portuguese, etc. There was almost no difference in the residential status of the users from the two groups.

\section{Details of diagnoses}

Figure 1 shows the distribution pattern of the level of learning disability between the two groups. There were more non-epileptic service users with mild learning disability (58\% non-epileptic v. 40\% epileptic) and almost equal number with moderate learning disability $31 \%$ and $26 \%$ ) in the two groups. Users with epilepsy were nearly

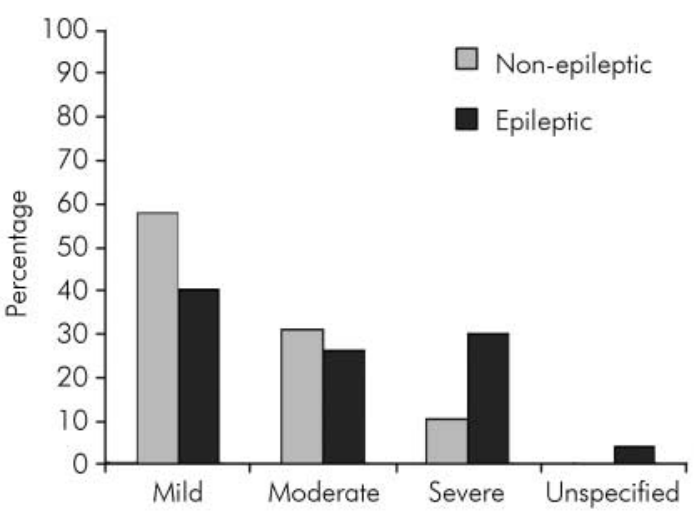

Fig. 1. Level of learning disabilities.

three times more likely to have severe learning disability than those without epilepsy (respectively $11 \%$ and $30 \%$ ).

Figure 2 depicts the distribution of challenging behaviour between the two groups: $70 \%$ of users with any type of challenging behaviour were in the nonepileptic group, as opposed to $59 \%$ in the epileptic group. Verbal challenging behaviour, which included shouting and swearing, was more common among those without epilepsy (35\%) than those with epilepsy (11\%). Physical challenging behaviour, for example physical assaults, damage to property, etc., was almost equally

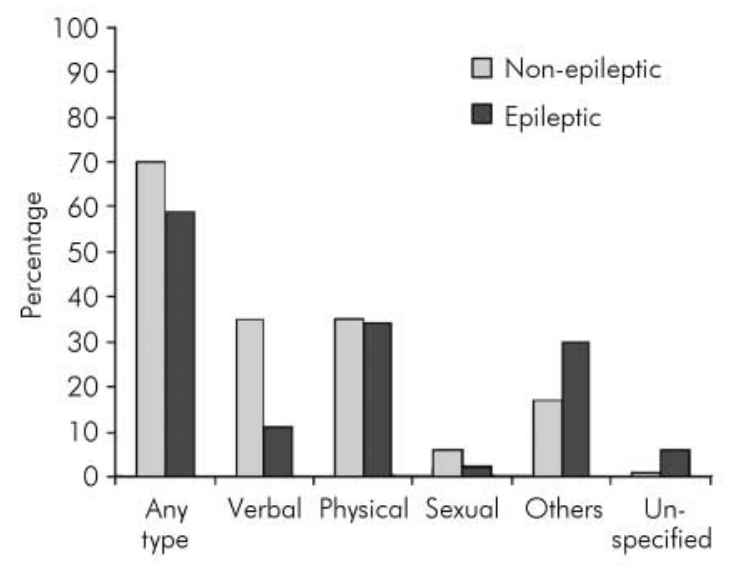

Fig. 2. Comorbid challenging behaviour.

\section{Table 2. Psychiatric comorbidity}

\begin{tabular}{|lcc}
\hline Common disorders & $\begin{array}{c}\text { Non-epileptic } \\
\text { group, } n(\%)\end{array}$ & $\begin{array}{c}\text { Epileptic } \\
\text { group, n (\%) }\end{array}$ \\
\hline Depression & $32(26)$ & $10(19)$ \\
Bipolar affective disorder & $8(6)$ & 0 \\
Anxiety disorders & $23(19)$ & $4(8)$ \\
Psychoses & $23(19)$ & $1(2)$ \\
Schizophrenia & $12(10)$ & $2(4)$ \\
Personality disorders & $6(5)$ & $1(2)$ \\
Autistic spectrum disorders & $13(11)$ & $5(9)$ \\
Dementia & $10(8)$ & $4(8)$ \\
Down syndrome & $8(6)$ & $3(6)$
\end{tabular}

original papers 
prevalent in the two groups (35\% and 34\%). Sexualised behaviour, in the form of indecent exposure, unconcealed masturbation, inappropriate touching, etc., was again more common in the non-epileptic group (6\% and $2 \%$ ). Physical challenging behaviour was the more common type among those with epilepsy. Other types of challenging behaviour, which included self-injurious behaviour, absconding, difficulty in engaging, deliberate falls, deliberate incontinence, rituals and hoarding food, among others, were more common among users with epilepsy (17\% and $30 \%)$.

As regards psychiatric conditions, depression was by far the most common diagnosis in both groups (Table 2), being slightly more common among people without epilepsy. Other conditions such as anxiety disorders, psychoses, schizophrenia and autistic-spectrum disorders were also prevalent among this group. There was no significant difference between the prevalence of conditions with an organic element such as dementia and Down syndrome between the two groups.

\section{Discussion}

Even though the total number of users included in the study $(n=177)$ was less than the actual number of service users on the practice database, we believe that all people requiring regular review of mental state and management have been included in the study. This is reflected by the high prevalence of challenging behaviour and psychiatric illnesses in both groups.

Our findings suggest that there is no increase in challenging behaviour in people with learning disability and epilepsy. This is especially true for the more 'conventional' types of behaviour such as verbal, physical and sexual challenging behaviours. The findings also suggest that having epilepsy does not increase the chance of developing psychiatric illnesses in people with learning disability. This is in keeping with the findings from other studies described in the published literature. This also confirms our postulation that there is no association between a high prevalence of mental and behavioural disorders with epilepsy in people with learning disability.

\section{Declaration of interest}

None.

\section{References}

CHUNG, M. C. \& CASSIDY, G. (2001) A preliminary report on the relationship between challenging behaviour and epilepsy in learning disability.

European Journal of Psychiatry, 15, 23-32.

COOPER, S. A. \& BAILEY, N. M. (2001) Psychiatric disorders amongst adults with learning disabilities - prevalence and relationship to ability level. Irish Journal of Psychological Medicine, 18 $45-53$.

DEB, S., THOMAS, M. \& BRIGHT, C. (2001) Mental disorder in adults with intellectual disability. 1: Prevalence of functional psychiatric illness among a community-based population aged between 16 and 64 years. Journal of Intellectual Disability Research, 45, 495-505.

ESPIE, C. A. WATKINS, J., CURTICE, L. et al (2003) Psychopathology in people with epilepsy and intellectual disability; an investigation of potential explanatory variables. Journal of Neurology, Neurosurgery and

Psychiatry with Practical Neurology, 74, 1485-1492.

KERR, M. P. (2002) Behavioral assessment in mentally retarded and developmentally disabled patients with

epilepsy. Epilepsy and Behavior, 3 (suppl 1), 14-17.

LONDON BOROUGH OF WALTHAM FOREST (2007) Spotlight: A Profile of Inequalities in Waltham Forest (Chapter 9: Ethnicity). London Borough of Waltham Forest (http:// www.walthamforest.gov.uk/chapter9-ethnicity.pdf).

OFFICE FOR NATIONAL STATISTICS (2003) Census 2001 Profiles: Waltham Forest. Office for National Statistics (http://www.statistics.gov.uk/ census2001/profiles/00BH-A.asp).

SMILEY, E. (2005) Epidemiology of mental health problems in adults with learning disability: an update. Advances in Psychiatric Treatment, 11, $214-222$.

TURKISTANI, I.Y. A. (2004) Epilepsy in learning disabilities: relevance and association with mental illness and behavioural disturbances. Journal of Intellectual Disabilities, 8, 89-99.

TYRER, F., MCGROTHER, C.W., THORP, C. F., et al (2006) Physical aggression towards others in adults with learning disabilities: prevalence and associated factors. Journal of Intellectual Disability Research, 50, 295-304.

*Deepak G. Pawar Specialist Registrar in Psychiatry of Learning Disabilities, North East London Mental Health NHS Trust, email: Deepak.Pawar@southessextrust.nhs.uk, Emmanuel O. Akuffo Consultant Psychiatrist in Psychiatry of Learning Disabilities, North East London Mental Health NHS Trust, London 